\begin{tabular}{|c|c|}
\hline 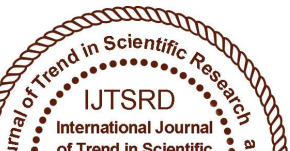 & $\begin{array}{l}\text { International Journal of Trend in Scientific } \\
\text { Research and Development (IJTSRD) }\end{array}$ \\
\hline 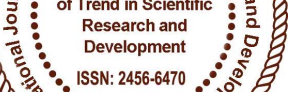 & International Open Access Journal \\
\hline 000 & ISSN No: 2456 - 6470 | www.ijtsrd.com | Volume - 2 | Issue - 3 \\
\hline
\end{tabular}

\title{
Experimental Analysis of Automotive Exhaust Heat Exchanger for Thermal Uniformity
}

\author{
Mr. Jadhav Vishal \\ Student, Department of Mechanical Engineering, \\ G. H. Raisoni College of Engineering and \\ Management, Pune, Maharashtra, India
}

\author{
Mr. D. S. Patil \\ Lecturer, Department of Mechanical Engineering, \\ G. H. Raisoni College of Engineering and \\ Management, Pune, Maharashtra, India
}

\begin{abstract}
The I.C. Engines are losing large amount of heat into environment directly. This waste heat can be reused for other purpose like TEG, Air conditioning etc. A heat exchanger is a device that is used to transfer thermal energy between two or more fluids, between a solid surface and a fluid, or between solid particulates and a fluid, at different temperatures and in thermal contact. In case of TEG there is need to have temperature uniformity on surface of heat exchanger is important. So, it is important design achieve thermal uniformity for converting the heat into other form of energy effectively.
\end{abstract}

Keywords: Exchangers, exhaust, uniformity, TEG, temperature

\section{INTRODUCTION:}

In today's world there is huge requirement of the new sources of the energy. So it is very important to create new sources or recover the waste heat through the various things like automobile, boiler, exhaust gases from heat producing devices etc. Heat exchanger is best device to recover the heat from the engines, boilers etc. So there various type of heat exchanger having different internal structures according to compatibility and application. In this work pipe type heat exchangers are used which are enclosed in rectangular cavity of the aluminium and ms steel. There are three different type of heat exchangers with different internal arrangements having different heat transfer rate according to time of exhaust gases remaining in that cavity. So which structures gives more time for gas to remain in the cavity without affects on the back pressure of the engine.

\section{Installation of position of heat exchanger:}

\subsection{Positioning of heat exchanger:}

The heat exchanger position is important for the more uniform heat distribution over the surface of the heat exchanger, also the working of the exhaust system should not get affected by the position of the heat exchanger. Back pressure should not increase by this work is very significant in this installation of the heat exchanger. The installation position of TEG and propose three different cases.

Case 1: Thermoelectric generator is situated at the last of exhaust system i.e. after muffler.

Case2: Thermoelectric generator situated in the middle of the catalytic convertor and the muffler.

Case 3: Thermoelectric generator is situated at the beginning i.e. before the catalytic convertor.

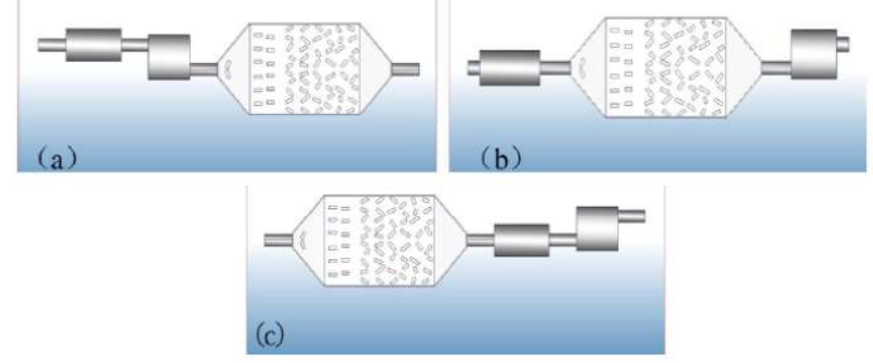

Fig1. Structures of three cases: (a) case1, (b) case2, and(c) case3. [8] 
In above cases case 2 is giving better results. The position in case second is better for the functional work of the exhaust system in which both the catalytic convertor and the muffler both are working properly.

\subsection{Analysis :}

The following figure shows that analysis of the exhaust system including catalytic convertor muffler, muffler and thermoelectric generator i.e. exhaust heat exchangers. The analysis has done for three different cases as mentioned in the figure below. The color shows the amount of heat produces in the TEG at three different positions in the exhaust system. In which the second position is producing better heat absorption in heat exchanger means to produce thermoelectric conversion.

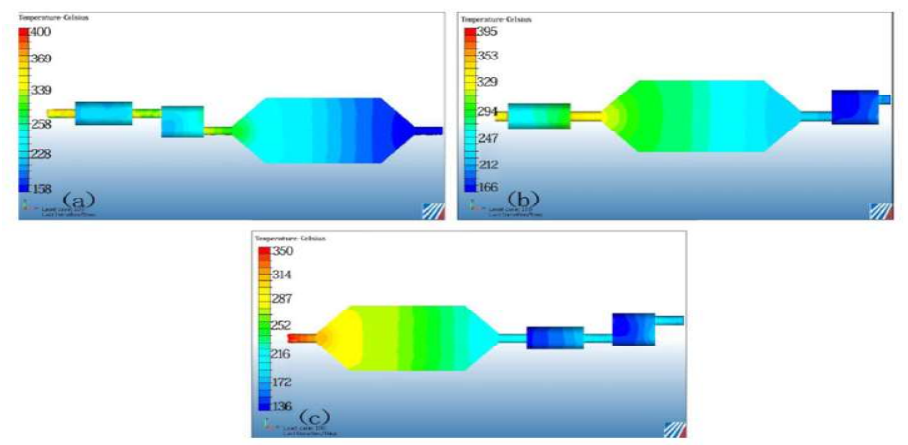

Fig2. Results from simulation under three cases :(a) case 1, (b) case2, and(c) case3.[8]

In case 1, Heat Exchanger was placed at the end of exhausted system, so the interface temperature of heat exchanger was just $210^{\circ} \mathrm{C}$ on average. The highest temperature was $240^{\circ} \mathrm{C}$ at the inlet and the minimum temperature was proximately $170^{\circ} \mathrm{C}$ at the outlet. In case 2, Heat Exchanger was located between catalytic converter (CC) and muffler (muf); the averaged surface temperature of exhaust heat exchangers was $270^{\circ} \mathrm{C}$ the interface temperature of the exchanger was uniform, which met the requirement of the thermoelectric exhaust system. In case 3, TEG was located upstream of catalytic converter (CC) and muffler (muf); the interface temperature of heat exchanger was $280^{\circ} \mathrm{C}$ on average, which was beneficial for arrangement of the heat exchanger. However, the highest temperature of $\mathrm{CC}$ was $230^{\circ} \mathrm{C}$, while the lowest was $160^{\circ} \mathrm{C}$; the average temperature of $\mathrm{CC}$ was just $190^{\circ} \mathrm{C}$ which could not reach the ignition temperature $\left(250^{\circ} \mathrm{C}\right)$ of harmful exhaust gas; $\mathrm{CC}$ was working under an abnormal condition.

\subsection{Simulation model (Six internal structures of exhaust heat exchangers)[1]}

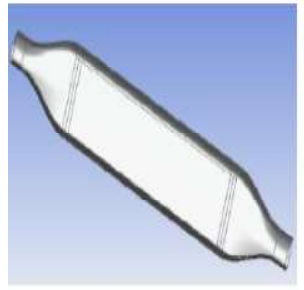

a) Empty cavity

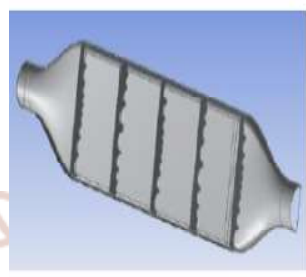

(d) Separate plate with holes e) Serial plate structure

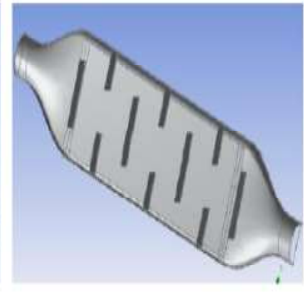

b) Inclined plate structure (c) parallel plate structure

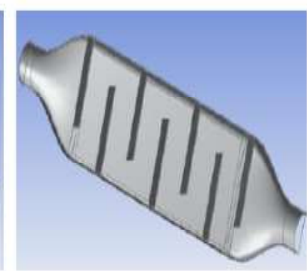

e) Pipe structure
Fig3: Six internal structures. [1]

For the purpose of comparison, 6 structures were made with the same dimensions. Each exhaust exchanger had a different internal structure: an inclined plate, a parallel plate structure, a separate plate with holes, a serial plate structure, and a novel pipe structure. In the above shown are internal design of the six different types of heat exchanger are shown. The piping type of heat exchangers is more preferable according to effect of back pressure and the thermal uniformity.

\section{Possible structures in Pipe Type Heat exchangers:}

a) Single inlet and single outlet

b) Double inlet and single outlet

c) Double inlet and double outlet

In these three cases third case is not suitable because of the high backpressure which effecting on the performance of heat exchanger. A test bench was developed to test muffler-like exhaust heat exchangers with different structures. The symmetrical 1-inlet 2outlet increased hydraulic disturbance and enhances heat transfer, resulting in the more uniform flow distribution and higher face temperature than the 2inlet 2-outlet and empty cavity. 


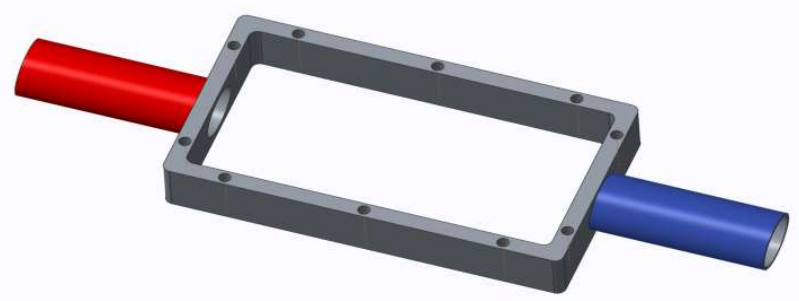

Case 1: single inlet and single outlet

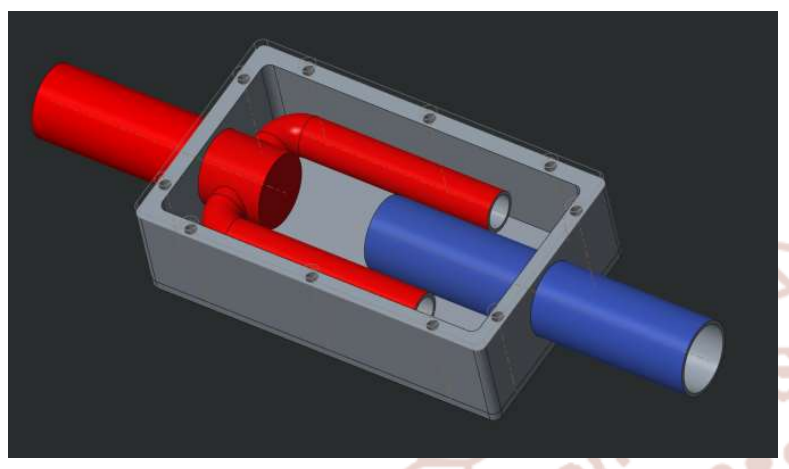

Case 2: Double inlet and single outlet

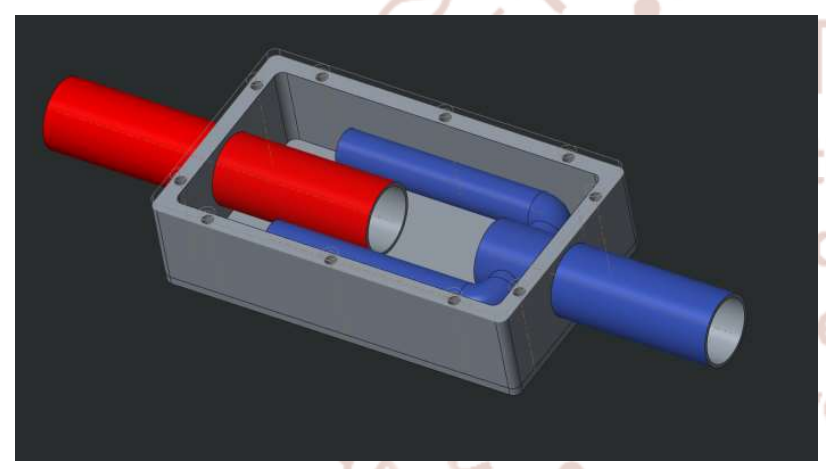

Case 3: single inlet and double outlet

Fig4: Internal structures of the heat exchanger

The surface temperature of exhaust heat exchangers was less than 100C, seriously holding up thermoelectric conversion efficiency. The structure geometry modification of heat exchanger in the next stage was the promotion of the variation of the velocity field and the uniformity of the temperature profile. 1-inlet 2-outlet, 2-inlet 2-outlet were $455 \mathrm{~Pa}$, $875 \mathrm{~Pa}$, equally $165 \%, 318 \%$ more than empty cavity in pressure drop when inlet temperature was $100 \mathrm{o} \mathrm{C}$ and mass flow rate was about $131 \mathrm{~kg} / \mathrm{h}$ and they were $1004 \mathrm{~Pa}, 2157 \mathrm{~Pa}$, equally 319\%, 523\% more when inlet temperature was $4000 \mathrm{C}$ and mass flow rate was about $156 \mathrm{~kg} / \mathrm{h}$. 2-Inlet 2-outlet among the three structures was always the largest in pressure drop and the most dependent to temperature and mass flow rate. As we know that the second case is more preferable then the possible variation in this two-inlet single outlet type heat exchanger is as below.

\section{Experimental Setup:}

The experiment is going to be conduct on I.C. engine which is having the variable compression ratio and the dynamometer for changing the loads on the engine. Also the engine is connected with the computer which is giving the continuous result including air flow fuel flow etc. This computer gives the results in the form of graphs as well.

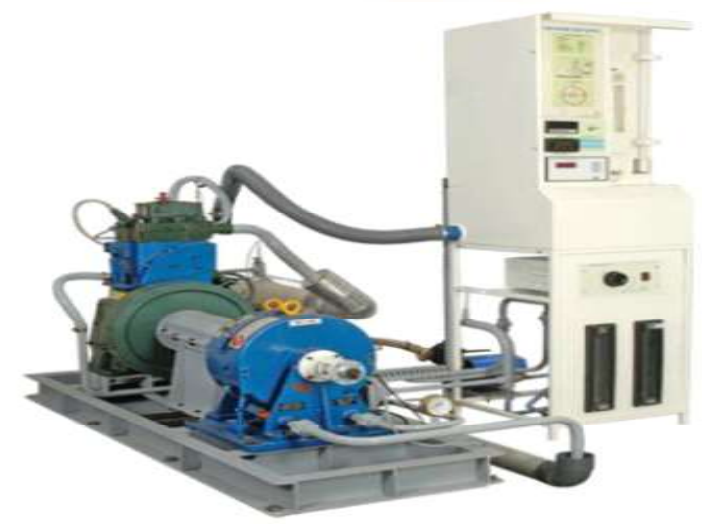

Fig5: Photografic diagram of engine.

\section{Layout of the experimental setup:}

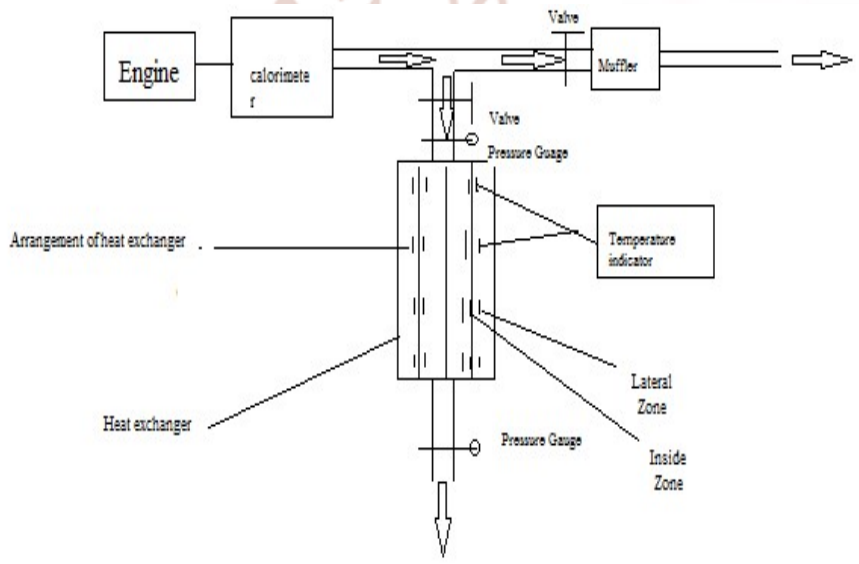

Case 1 and Case 2 are more preferable for the experiment.As shown in above figure the heat exchanger amoungst thease two are choose and set on the exhaust system and its uniformity is being checked

\section{Calculations:}

The calculations has performed on the basis of the formula of thermal uniformity.

$$
\lambda=1-\frac{1}{\sqrt{8}} \sum_{i=1}^{y} \frac{\sqrt{\left(t_{i}-t_{\text {mean }}\right)^{2}}}{t_{\text {mean }}}
$$

$\lambda=$ temp. Uniformity Coefficient (0-1)

$y=$ No of thermocouple placed on the surface

$\mathrm{ti}=$ Temp. at measurement position $\mathrm{j}$

tmean $=$ Average temp. of HX plat 
International Journal of Trend in Scientific Research and Development (IJTSRD) ISSN: 2456-6470

\section{Results Discussion:}

Table 1: Comparison on Full Load Conditions

\begin{tabular}{|c|c|c|c|c|}
\hline & $\begin{array}{c}\text { Engine Load } \\
(\mathrm{kg})\end{array}$ & $\begin{array}{c}\text { Wall Average } \\
\text { Temperature (c) }\end{array}$ & $\begin{array}{c}\text { Back Pressure } \\
(\text { Pa) }\end{array}$ & $\begin{array}{c}\text { Temp } \\
\text { Uniformity } \\
\text { Coefficient }\end{array}$ \\
\hline $\begin{array}{c}\text { Case I: Single Inlet and } \\
\text { Single Outlet }\end{array}$ & 9 & 45.25 & 150 & 0.9875 \\
\hline $\begin{array}{c}\text { Case II: Double Inlet } \\
\text { and Single Outlet }\end{array}$ & 9 & 102.75 & 250 & 0.9938 \\
\hline $\begin{array}{c}\text { Case III: Single Inlet } \\
\text { and Double Outlet }\end{array}$ & 9 & 100.875 & 300 & 0.9950 \\
\hline
\end{tabular}

\section{Conclusion:}

In Case III which gives the better thermal uniformity as compare to the other two cases. So the Case III i.e. single inlet and double outlet case gives better temperature uniformity.

$>$ Back pressure is higher in case of Case II. Then Case III having some less amount of back pressure. In case I there is lesser back pressure.

$>$ Case III is good in uniformity but case II gives more wall temperature.

\section{References:}

1) Shengqiang Bai, HongliangLu,et N al; Numerical and experimental analysis for exhaust heat exchangers in automobile thermoelectric generators, Case StudiesinThermalEngineering4(2014)99-112.

2) C.Q. Su, W.S. Wang, X. Liu, Y. D. Deng, Simulation and experimental study on thermal optimization of the heat exchanger for automotive exhaust-based thermoelectric generators, Case StudiesinThermalEngineering4(2014)85-91

3) Yiping Wang Shuai Li, Xue Yang, Yadong Deng, and Chuqi Su, Numerical and Experimental Investigation for Heat Transfer Enhancement by Dimpled Surface Heat Exchanger in Thermoelectric Generator, 2015 The Minerals, Metals \& Materials Society
4) Tongcai Wang, Weiling Luan, Wei Wang, Shan-Tung Tu Waste heat recovery through plate heat exchanger based thermoelectric generator system, Applied Energy 136 (2014) $860-865$.

5) ZhiqiangNiu, Hai Diao, Shuhai Yu, Kui Jiao, Qing Du; Investigation and design optimization of exhaust-based thermoelectric generator system for internal combustion engine. Energy Conversion and Management 85 (2014) 85-101

6) R. Saidur, M. Rezaei, W. K. Muzammil, M. H. Hassan,S. Paria, M. Hasanuzzaman, Technologies to recover exhaust heat from internal combustion engines, Renewable an Sustainable Energy Reviews 16 (2012) 5649_ 5659.

7) X. Liu, Y.D. Deng, S. Chen, W.S. Wang, Y. $\mathrm{Xu}, \mathrm{C} . \mathrm{Q}$. Su; A case study on compatibility of automotive exhaust thermoelectric generation system, catalytic converter and muffler Case StudiesinThermalEngineering2(2014)62-66

8) Lu Hongliang, $\mathrm{Wu}$ Ting. Experiment on thermal uniformity and pressure drop of exhaust heat exchanger for automotive thermoelectric generator. Energy 2013; 54:372-7.

9) TambaleShahanavaj, Pandhare Nitin T, zardeskar Santosh J, Khandekar S.B,Experimental Investigation of performance of plate heat exchanger as working fluid

10) eISSN: 2319-1163 | pISSN: 2321-7308 